\title{
Novel kojic acid-polymer-based magnetic nanocomposites for medical applications
}

This article was published in the following Dove Press journal:

International Journal of Nanomedicine

7 January 2014

Number of times this article has been viewed

\author{
Samer Hasan Hussein-Al- \\ $\mathrm{Ali}^{\prime}$ \\ Mohamed Ezzat El \\ Zowalaty ${ }^{2,5}$ \\ Mohd Zobir Hussein ${ }^{3}$ \\ Maznah Ismail ${ }^{1,4}$ \\ Dena Dorniani ${ }^{3}$ \\ Thomas J Webster ${ }^{6,7}$ \\ 'Laboratory of Molecular \\ Biomedicine, ${ }^{2}$ Laboratory of Vaccines \\ and Immunotherapeutics, Institute of \\ Bioscience, ${ }^{3}$ Materials Synthesis and \\ Characterization Laboratory, Institute \\ of Advanced Technology, ${ }^{4}$ Department \\ of Nutrition and Dietetics, Faculty \\ of Medicine and Health Science, \\ Universiti Putra Malaysia, Serdang, \\ Selangor, Malaysia; ${ }^{5}$ Faculty of Public \\ Health and Tropical Medicine, Jazan \\ University, Jazan, Saudi Arabia; \\ ${ }^{6}$ Department of Chemical Engineering \\ and Program in Bioengineering, \\ Northeastern University, Boston, \\ MA, USA; ${ }^{7}$ Center of Excellence for \\ Advanced Materials Research, King \\ Abdulaziz University, Jeddah, Saudi \\ Arabia
}

Correspondence: Mohd Zobir Hussein Materials Synthesis and Characterization Laboratory, Institute of Advanced Technology, Universiti Putra Malaysia, Serdang, Selangor 43400, Malaysia Tel +60389466801 Fax +60389435380 Email mzobir@upm.edu.my
Abstract: Iron oxide magnetic nanoparticles (MNPs) were synthesized by the coprecipitation of iron salts in sodium hydroxide followed by coating separately with chitosan (CS) and polyethylene glycol (PEG) to form CS-MNPs and PEG-MNPs nanoparticles, respectively. They were then loaded with kojic acid (KA), a pharmacologically bioactive natural compound, to form KA-CSMNPs and KA-PEG-MNPs nanocomposites, respectively. The MNPs and their nanocomposites were characterized using powder X-ray diffraction, Fourier transform infrared spectroscopy, thermogravimetric analysis, vibrating sample magnetometry, and scanning electron microscopy. The powder X-ray diffraction data suggest that all formulations consisted of highly crystalline, pure magnetite $\mathrm{Fe}_{3} \mathrm{O}_{4}$. The Fourier transform infrared spectroscopy and thermogravimetric analysis confirmed the presence of both polymers and KA in the nanocomposites. Magnetization curves showed that both nanocomposites (KA-CS-MNPs and KA-PEG-MNPs) were superparamagnetic with saturation magnetizations of $8.1 \mathrm{emu} / \mathrm{g}$ and $26.4 \mathrm{emu} / \mathrm{g}$, respectively. The KA drug loading was estimated using ultraviolet-visible spectroscopy, which gave a loading of $12.2 \%$ and $8.3 \%$ for the KA-CS-MNPs and KA-PEG-MNPs nanocomposites, respectively. The release profile of the KA from the nanocomposites followed a pseudo second-order kinetic model. The agar diffusion test was performed to evaluate the antimicrobial activity for both KA-CS-MNPs and KA-PEG-MNPs nanocomposites against a number of microorganisms using two Gram-positive (methicillin-resistant Staphylococcus aureus and Bacillus subtilis) and one Gram-negative (Salmonella enterica) species, and showed some antibacterial activity, which could be enhanced in future studies by optimizing drug loading. This study provided evidence for the promise for the further investigation of the possible beneficial biological activities of KA and both KA-CSMNPs and KA-PEG-MNPs nanocomposites in nanopharmaceutical applications.

Keywords: chitosan, polyethylene glycol, magnetic nanoparticle, kojic acid, controlled release, biological activity

\section{Introduction}

Chemotherapy is the treatment of cancer with cytotoxic antineoplastic drugs. It is given to patients for treatment, or it may aim to prolong lifetimes or to palliate cancer symptoms. Traditional chemotherapy has limitations such as immunosuppression, ${ }^{1}$ mucositis, ${ }^{2}$ and alopecia. ${ }^{3}$ These limitations are due to the nonselectivity of antineoplastic drugs, thus affecting normal cells as well as cancerous cells. This has encouraged pioneering therapeutic strategies where the drug is delivered at a targeted cancer site. ${ }^{4,5}$ Targeted drug delivery is the best way to accumulate active drug molecules in pathological areas and minimize the side effects of antineoplastic drugs. ${ }^{6}$ Due to their ability to penetrate cells and possess prolonged circulation times, nanoparticles have extensive potential for chemotherapeutical applications. In this regard, superparamagnetic iron oxide magnetic 
nanoparticles (MNPs) and other nanoparticles coated with polymers have received considerable attention in the biomedical field. ${ }^{7,8}$ The application of magnetic nanoparticles in drug delivery systems depends on the use of an external magnetic field to avoid problems associated with traditional chemotherapy. ${ }^{9-11}$ Coated magnetic nanoparticles loaded with anticancer drugs can then be injected into the patient's body via the circulatory system to develop a highly desirable ondemand drug delivery system. By using an external magnetic field, the nanoparticles, and thus drug, can localize only to tumor cells, and then the drug can be released locally from the nanocarriers to enter the cells. It has been shown that such magnetic nanoparticles caused a complete reduction in tumor cells without any negative side effects..$^{10,12}$

Such work in cancer has forged a pathway to use magnetic nanoparticles for other medical applications. For example, several studies on model drug-loaded MNPs have been reported, including doxorubicin, ${ }^{13-16}$ 5-aminosalicylic acid, ${ }^{17}$ insulin, ${ }^{18}$ 10-hydroxy camptothecin, ${ }^{19}$ gallic acid, ${ }^{20}$ folic acid, ${ }^{21}$ diclofenac sodium, ${ }^{22}$ and dexamethasone. ${ }^{23}$ It has been found that superparamagnetic MNPs are predisposed to aggregate due to strong dipole-dipole attractions. So, the modification of the surface of the superparamagnetic MNPs with biocompatible and biodegradable polymers can minimize their agglomeration while serving as a drug carrier. These polymers include chitosan (CS) and its derivatives, polysaccharides, and polyethylene glycol (PEG).

Along these lines, kojic acid (KA) (5-hydroxy-2hydroxymethyl-4-pyranone), a secondary metabolite, is one of the oldest identified (dating back to 1903) natural antibiotics produced by filamentous fungi and bacteria of many species of Aspergillus, and Penicillium, and Acetobacter. ${ }^{24-27} \mathrm{KA}$ is a natural compound of interest due to its low side effects and its polyfunctional structure that allows the development of a variety of biologically active compounds and pharmaceuticals. ${ }^{28,29} \mathrm{KA}^{30}$ and its derivatives have been used in a variety of medical, food, agricultural, and industrial applications, such as an antibrowning agent (antispeck) and antioxidant; ${ }^{31-33}$ for skin care, antiacne, and cosmetic applications due to its potent skin lightening/depigmenting properties, ${ }^{34-37}$ and used for herbicide, insecticide, pesticide, ${ }^{38-41}$ antidiabetic, ${ }^{42}$ antitumor, ${ }^{43}$ antiproliferative, ${ }^{44}$ anticonvulsant, ${ }^{31}$ and antimicrobial (including both antibacterial and antifungal) activities. ${ }^{29,45-48}$ In addition, it has also been shown that KA significantly enhances neutrophil phagocytosis and lymphocyte proliferation. ${ }^{49,50}$

In this study, we have incorporated CS and PEG on the surface of MNPs as a first attempt to use them in antibacterial applications. Due to the importance of KA (and its derivatives) in antibacterial applications, as shown from the previous pharmacological studies, KA was chosen as the model active substance in this study. Thus, the aim of the study was to synthesize and characterize novel magnetic nanocomposites containing KA and study their release profile as well as to investigate the antimicrobial activity of these novel magnetic nanocomposites.

\section{Materials and methods \\ Materials}

All chemicals used in this study were reagent grade and were used as such without purification. Ferrous chloride tetrahydrate $\left(\mathrm{FeCl}_{2} \cdot 4 \mathrm{H}_{2} \mathrm{O}\right)(>99 \%)$, ferric chloride hexahydrate $\left(\mathrm{FeCl}_{3} \cdot 6 \mathrm{H}_{2} \mathrm{O}\right)(99 \%)$, and streptomycin sulfate were obtained from Merck KGaA (Darmstadt, Germany). Low molecular weight CS (deacetylation 75\%-85\%), PEG, KA (>98\% purity; molecular weight $142.11 \mathrm{~g} / \mathrm{mol}$ ), and ampicillin were purchased from Sigma-Aldrich (Saint Louis, MO, USA) and were used as such without any pretreatment. Acetic acid (99.8\%) was purchased from Hamburg Industries, Inc (Hamburg, Germany). Deionized water was used for all the experiments.

\section{Preparation of MNPs}

The MNPs were prepared by a coprecipitation method as previously described. ${ }^{32,33}$ The MNPs were prepared by mixing solutions of $\mathrm{Fe}^{2+}(0.15 \mathrm{~mol})$ and $\mathrm{Fe}^{3+}(0.3 \mathrm{~mol})$ in $40 \mathrm{~mL}$ of deionized water. The Fe ion solutions were added to a solution of $\mathrm{NaOH}(2 \mathrm{~mol})$ and the $\mathrm{pH}$ value of the solution was kept above 10. The MNPs precipitates were produced according to the reaction,

$$
2 \mathrm{FeCl}_{3}+\mathrm{FeCl}_{2}+8 \mathrm{NaOH} \rightarrow \mathrm{Fe}_{3} \mathrm{O}_{4}+8 \mathrm{NaCl}+4 \mathrm{H}_{2} \mathrm{O}
$$

The solution was sonicated for 60 minutes at room temperature. Finally, the precipitates were collected by centrifugal separation and were separately washed three times with deionized water.

\section{Preparations of CS-MNPs and PEG-MNPs}

MNPs surfaces were modified using CS and PEG polymers and were prepared as follows: the CS solution was prepared by dissolving $0.5 \mathrm{~g}$ of CS powder in a $1 \%$ acetic acid solution. Similarly, the PEG solution was prepared by dissolving $0.5 \mathrm{~g}$ of the polymer into $100 \mathrm{~mL}$ of water. CS coated magnetic nanoparticles (CS-MNPs) and PEG coated magnetic nanoparticles (PEG-MNPs) were prepared by mixing CS and PEG 
solutions $(40 \mathrm{~mL})$, respectively, with a $10 \mathrm{~mL}$ suspension of $\mathrm{Fe}_{3} \mathrm{O}_{4}$ nanoparticles $(50 \mathrm{mg} / \mathrm{mL})$. The mixtures were stirred for 18 hours. Coated particles were separated by a permanent magnet and dried at $70^{\circ} \mathrm{C}$ for 2 hours.

\section{Preparation of KA-CS-MNPs and KA-PEG-MNPs nanocomposites}

KA-CS-MNPs (kojic acid-loaded chitosan coated magnetic nanoparticles) and KA-PEG-MNPs (kojic acid-loaded PEG coated magnetic nanoparticles) nanocomposites were prepared by mixing $5 \mathrm{mg} / \mathrm{mL}$ of KA with a known weight of each CS-MNPs and PEG-MNPs nanoparticles (40 mg/mL). The solutions were magnetically stirred at room temperature for 18 hours to facilitate the uptake of KA. Next, the products were separated using a permanent magnet.

\section{Loading and release amounts of KA from KA-CS-MNPs and KA-PEG-MNPs nanocomposites}

The percentage of KA loaded in the nanocomposite was measured spectrophotometrically. A measure of $5 \mathrm{mg}$ of the nanocomposite was dissolved in concentrate $\mathrm{HCl} / \mathrm{HNO} 3$, then the amount of the KA in the sample was measured using UV-VIS spectroscopy. KA release profiles from the nanocomposites were determined at room temperature using a phosphate-buffered saline solution (PBS) at a concentration of $0.01 \mathrm{M}$ at $\mathrm{pH} 7.4$. About $85 \mathrm{mg}$ of the nanocomposites were added to $500 \mathrm{~mL}$ of the PBS media. The cumulative amount of KA released into the solution was measured at preset time intervals at $\lambda_{\max }=218 \mathrm{~nm}$ using a UV-Vis spectrophotometer, model Lambda 35 (Perkin Elmer, Waltham, MA, USA). To compare the release rate of KA from KACS-MNPs and KA-PEG-MNPs nanocomposites with the physical mixture which contained KA with polymers and MNPs, approximately $1.0 \mathrm{mg}$ of the physical mixture was obtained by mixing $0.14 \mathrm{mg}$ KA with the $0.05 \mathrm{mg} \mathrm{CS}$ and $0.81 \mathrm{mg}$ MNPs. In addition, $0.11 \mathrm{mg}$ of KA was mixed with $0.17 \mathrm{mg}$ PEG and $0.73 \mathrm{mg}$ MNPs, which was used to compare with the release from the KA-PEG-MNPs. The release of the active KA was determined as described above.

\section{Antimicrobial activity of KA nanocomposites}

Two Gram-positive bacteria (methicillin-resistant Staphylococcus aureus and Bacillus subtilis) and one Gram-negative species (Salmonella enterica) were used to test the ability of the synthesized nanocomposites to inhibit bacteria and fungi. The microbial cultures were obtained from the microbial culture collection unit (UNiCC, Institute of Bioscience, Universiti Putra Malaysia). Bacterial cultures were maintained on Luria-Bertani (LB) agar (SigmaAldrich). Prior to incubation with the novel nanoparticles, bacteria were cultured overnight in $5 \mathrm{~mL}$ of LB broth (SigmaAldrich) in a Certomat BS-T incubation shaker (Sartorius, Goettingen, Germany) at $37^{\circ} \mathrm{C}$, set to $150 \mathrm{rpm}$ until the culture reached an optical density at a wavelength of $600 \mathrm{~nm}$ of 1.0 (Spekol UV VIS 3.02; AnalytikJena, Jena, Germany), corresponding to $10^{8} \mathrm{CFU} / \mathrm{mL}$.

The antimicrobial activities of the synthesized nanocomposites were evaluated against the aforementioned bacteria using the agar diffusion (cup diffusion) method according to the Clinical and Laboratory Standards Institute guidelines. ${ }^{51}$ Briefly, a volume of $20 \mathrm{~mL}$ of liquid Mueller Hinton agar (pH 7.3 \pm 0.2 at $25^{\circ} \mathrm{C}$ ) was poured onto disposable sterilized Petri dishes and allowed to solidify. The surfaces of the solidified agar plates were allowed to dry in the incubator prior to streaking of microorganisms onto the surface of the agar plates. Next, $100 \mu \mathrm{L}$ of the microbial culture suspensions in LB broth was streaked over the dried surface of the agar plate and spread uniformly using sterilized glass rods and allowed to dry before use. The nanocomposites were suspended in sterilized distilled water. Next, wells were made at equal distances in the agar plates using a sterilized cork borer and were filled with the corresponding nanocomposite suspensions $(150 \mu \mathrm{L})$, and the same concentration $(100 \mu \mathrm{g} / \mathrm{mL})$ of KA and control antibiotics (ampicillin for Gram-negative and streptomycin for Gram-positive) was added to a separate well. To test the antimicrobial effect of the nanocomposites after release, the nanocomposites were suspended in PBS, and the test was repeated as described above. The experiment was carried out in triplicate, and the diameters of the zones of inhibition were measured to the nearest millimeter after 24 hours of incubation at $37^{\circ} \mathrm{C}$.

\section{Instrumentation}

Powder X-ray diffraction (XRD) patterns were used to determine the crystal structure of the samples in the range of 20-70 degrees on an XRD-6000 diffractometer (Shimadzu, Tokyo, Japan) using $\mathrm{CuK}_{\alpha}$ radiation $(\lambda 1.5406 \AA)$ at $30 \mathrm{kV}$ and $30 \mathrm{~mA}$. Fourier transform infrared spectroscopy (FTIR) spectra of the materials were recorded over the range of $400-4,000 \mathrm{~cm}^{-1}$ on a Thermo Nicolet Nexus, Smart Orbit spectrometer using the potassium bromide disc method. Thermogravimetric analysis (TGA) was carried out using a Metter-Toledo 851e instrument (Greifensee, Switzerland) 
with a heating rate of $10^{\circ} \mathrm{C} /$ minute in $150 \mu \mathrm{L}$ alumina crucibles and in the range of $30^{\circ} \mathrm{C}-900^{\circ} \mathrm{C}$. Scanning electron microscopy (SEM) was used to observe the surface morphology of the samples using a NOVA ${ }^{\text {TM }}$ NanoSEM 230 (FEI, Hillsboro, OR, USA) scanning electron microscope. Magnetic properties were evaluated by a Lakeshore 7404 vibrating sample magnetometer (Westerville, OH, USA). An ultraviolet-visible spectrophotometer (Perkin Elmer) was used for the controlled release study.

\section{Results and discussion XRD}

The XRD patterns of the prepared MNPs as well as KACS-MNPs and KA-PEG-MNPs nanocomposites are shown in Figure $1 \mathrm{~A}-\mathrm{C}$, respectively. Figure 1A shows six characteristic peaks for MNPs marked by their indices 220, $311,400,422,511$, and 440 which appeared at $2 \theta=30.1^{\circ}$, $35.4^{\circ}, 43.2^{\circ}, 53.4^{\circ}, 57.0^{\circ}$, and $62.6^{\circ}$, respectively, which suggests the formation of spinel structure of iron oxide (magnetite- $\left.\mathrm{Fe}_{3} \mathrm{O}_{4}\right) \cdot{ }^{1,25}$ These were observed also for both

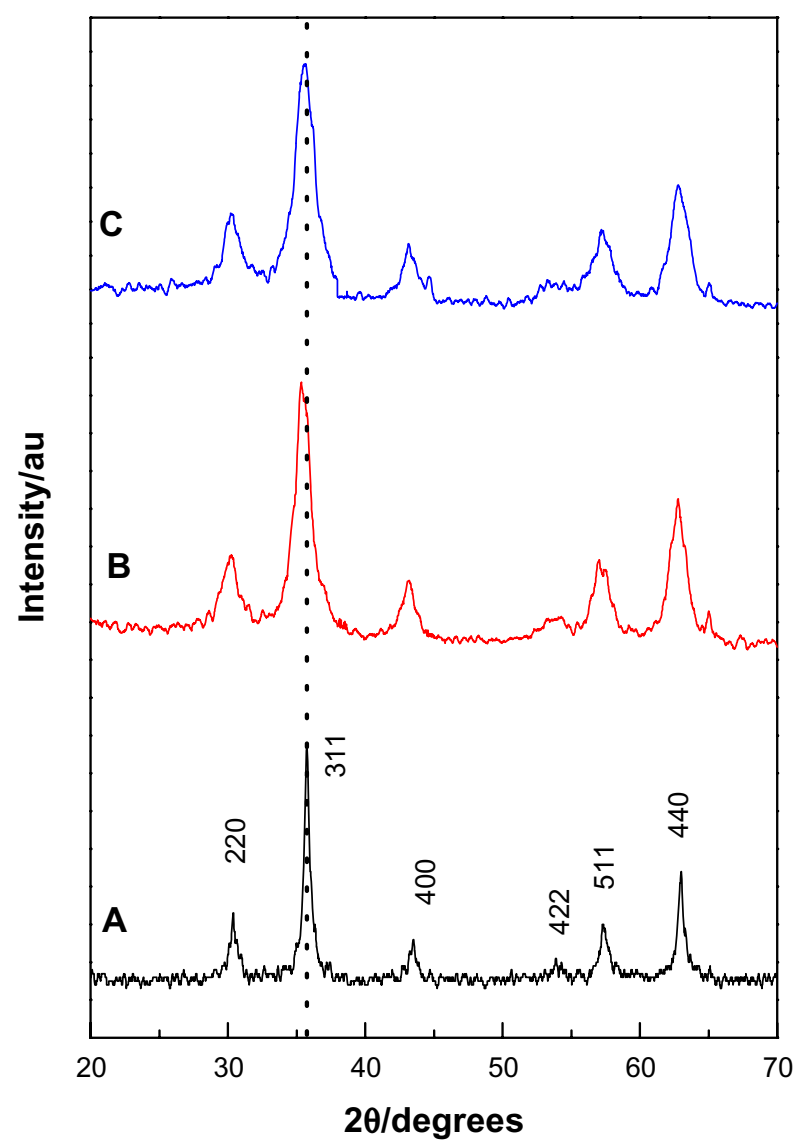

Figure I Powder X-ray diffraction patterns of (A) MNPs, (B) KA-CS-MNPs, and (C) KA-PEG-MNPs nanocomposites.

Abbreviations: KA-CS-MNPs, kojic acid-chitosan-iron oxide nanoparticles; KAPEG-MNPs, kojic acid-polyethylene glycol-iron oxide nanoparticles; MNPs, iron oxide magnetic nanoparticles. nanocomposite samples in Figure $1 \mathrm{~B}$ and $\mathrm{C}$, which indicates that the coating of both polymers and drug loading process did not result in any phase change for the MNPs.

The mean grain size was calculated using the DebyeScherrer formula as shown in the equation,

$$
\mathrm{D}=\frac{k \lambda}{\beta \cos \theta}
$$

where $\mathrm{D}$ is average grain size, $k$ is Scherrer constant (0.89), $\lambda$ is the $\mathrm{X}$-ray diffraction wavelength $(0.15418 \mathrm{~nm}), \beta$ is the peak width of half maximum intensity, and $\theta$ is the Bragg diffraction angle. The estimation of the average crystal size for the KA-CS-MNPs and KA-PEG-MNPs nanocomposites were calculated to be $19.2 \mathrm{~nm}$ and $16.7 \mathrm{~nm}$, respectively.

\section{FTIR}

FTIR spectra for MNPs, KA-CS-MNPs, KA-PEG-MNPs, and free KA drug are shown in Figure 2. The MNPs in Figure $2 \mathrm{~A}$ showed an absorption band at $565 \mathrm{~cm}^{-1}$, which is due

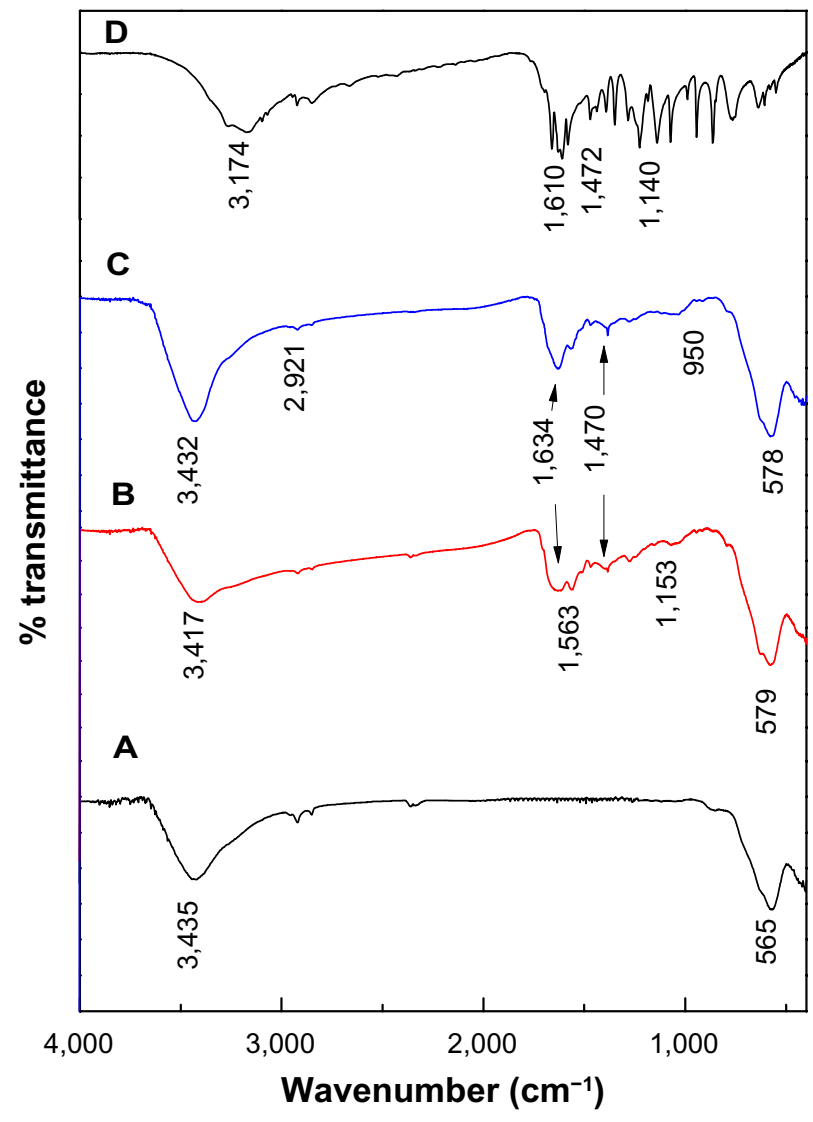

Figure 2 FTIR spectra of (A) MNPs, (B) KA-CS-MNPs, (C) KA-PEG-MNPs, and (D) free KA.

Abbreviations: FTIR, Fourier transform infrared spectroscopy; KA, kojic acid; KA-CS-MNPs, kojic acid-chitosan-iron oxide nanoparticles; KA-PEG-MNPs, kojic acid-polyethylene glycol-iron oxide nanoparticles; MNPs, iron oxide magnetic nanoparticles. 
to the stretching of $\mathrm{Fe}-\mathrm{O}$ in $\mathrm{Fe}_{3} \mathrm{O}_{4}$. However, this characteristic band of $\mathrm{Fe}-\mathrm{O}$ was shifted to $579 \mathrm{~cm}^{-1}$ and $578 \mathrm{~cm}^{-1}$ for KA-CS-MNPs and KA-PEG-MNPs, respectively. This result confirmed the presence of magnetite nanoparticles. ${ }^{52}$

The FTIR spectra for KA-CS-MNPs and KA-PEG-MNPs nanocomposites showed the characteristic bands for CS and PEG, respectively, proving that magnetite nanoparticles were successfully coated with CS and PEG. For example in the KA-CS-MNPs nanocomposite, a band around $1,563 \mathrm{~cm}^{-1}$ was assigned to $\mathrm{NH}_{3}{ }^{+}{ }^{53}$ The bands at $1,153 \mathrm{~cm}^{-1}$ are due the C-N stretch in CS. ${ }^{52}$ The FTIR spectra of the KA-PEGMNPs nanocomposite are shown in Figure 2C. The bands around $2,921 \mathrm{~cm}^{-1}$ and $950 \mathrm{~cm}^{-1}$ were due to $-\mathrm{CH}_{2}$ stretching vibrations and $-\mathrm{CH}$ out-of-plane bending vibrations, respectively. ${ }^{54} \mathrm{The}-\mathrm{CH}_{2}$ and $-\mathrm{CH}$ bands are strong evidence that PEG covered the nanoparticle surface.

The appearance of KA bands in KA-CS-MNPs and KAPEG-MNPs nanocomposites confirmed the loading of KA on the CS-MNPs and PEG-MNPs nanoparticle surface; for example, there is a band at $1,634 \mathrm{~cm}^{-1}$. In addition, the band at $1,610 \mathrm{~cm}^{-1}$, which relates to the $\mathrm{C}=\mathrm{O}$ of free $\mathrm{KA}$ was shifted to $1,563 \mathrm{~cm}^{-1}$ and $1,568 \mathrm{~cm}^{-1}$ in KA-CS-MNPs and KA-PEG-MNPs nanocomposites, respectively. This shifting was due to the loading of KA and binding with polymers by hydrogen bonds.

Figure 3 shows the interaction between the MNPs and the polymers, and it is clear that the MNPs interacted with CS by the glycosidic bonds, ${ }^{19}$ whereas it interacted with PEG by hydrogen bonds. In addition, the KA drugs interacted with both polymers by hydrogen bonds.

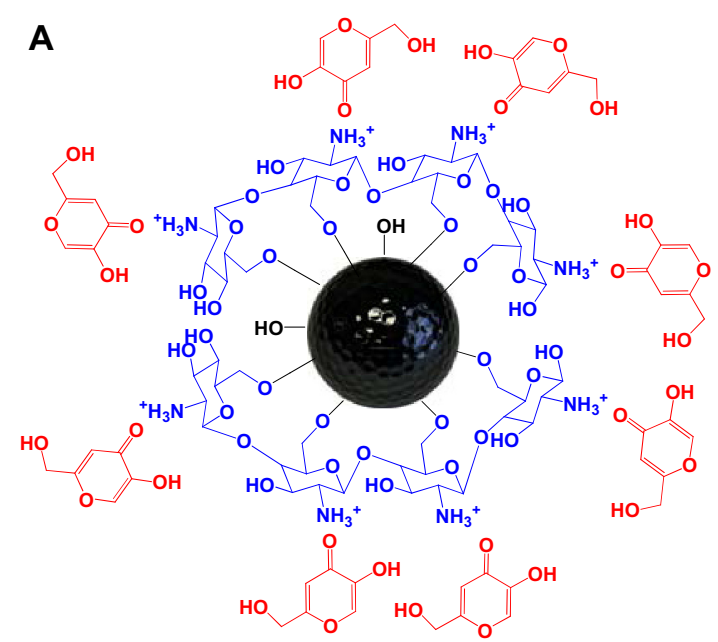

\section{TGA}

The thermal behavior of the MNPs before and after polymer coating and KA loading was further examined using TGA. The thermal analyses of MNPs, CS-MNPs, and KA-CS-MNPs are shown in Figure 4A, and the thermal analyses of MNPs, PEG-MNPs, and KA-PEG-MNPs are shown in Figure 4B. For MNPs, two main thermal events were clearly observed. The first event, which occurred in the region of $30^{\circ} \mathrm{C}-220^{\circ} \mathrm{C}$, was attributed to the removal of surface hydroxyl groups and/or adsorbed water with a $3.9 \%$ weight loss. ${ }^{12}$ This was followed by the second stage at $220^{\circ} \mathrm{C}-850^{\circ} \mathrm{C}$ with a $1.9 \%$ weight loss. The thermal analyses for CS-MNPs and PEG-MNPs showed a slight weight loss up to $260^{\circ} \mathrm{C}$, which probably was due to the adsorbed water. Significant weight loss for CS-MNPs and PEG-MNPs was noticed between $260^{\circ} \mathrm{C}$ and $620^{\circ} \mathrm{C}$, with $7.2 \%$ and $9.4 \%$ weight loss, respectively. These significant weight losses were attributed to the decomposition of CS and PEG polymers which absorbed on the surface of MNPs (see inset curve for Figure 4A and B). By comparing the weight loss curves of CS-MNPs and PEG-MNPs nanocomposites with MNPs, the data suggested that the amount of CS and PEG in CS-MNPs and PEG-MNPs was estimated at 5.3\% and $7.5 \%$, respectively.

TGA thermal analysis can be used to also confirm the loading of KA at the surface of CS-MNPs and PEG-MNPs. A significant weight loss was noticed between $260^{\circ} \mathrm{C}$ and $600^{\circ} \mathrm{C}$, with $20.7 \%$ and $19.9 \%$ total weight loss for KACS-MNPs and KA-PEG-MNPs, respectively. This weight

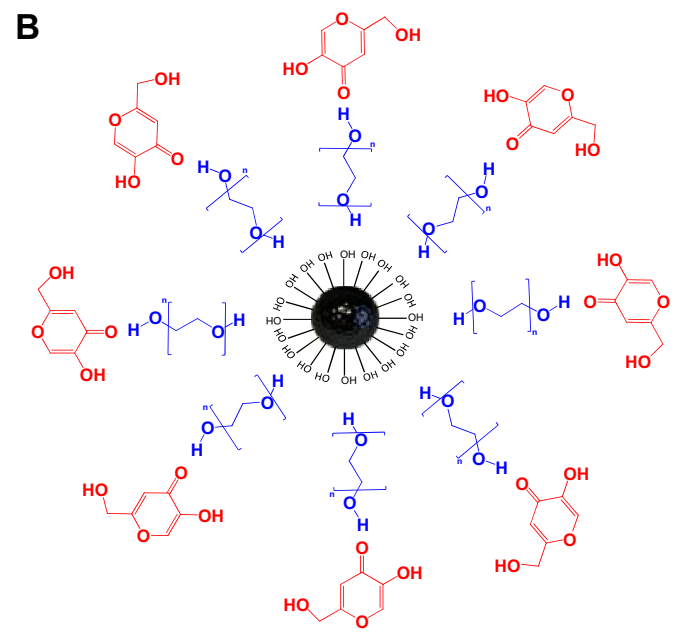

Figure 3 Schematic representation of the interaction between KA, CS, and MNPs in the KA-CS-MNPs nanocomposite (A) and between KA, PEG, and MNPs in the KAPEG-MNPs nanocomposite (B).

Abbreviations: CS, chitosan; KA, kojic acid; KA-CS-MNPs, kojic acid-chitosan-iron oxide nanoparticles; KA-PEG-MNPs, kojic acid-polyethylene glycol-iron oxide nanoparticles; MNPs, iron oxide magnetic nanoparticles; PEG, polyethylene glycol. 

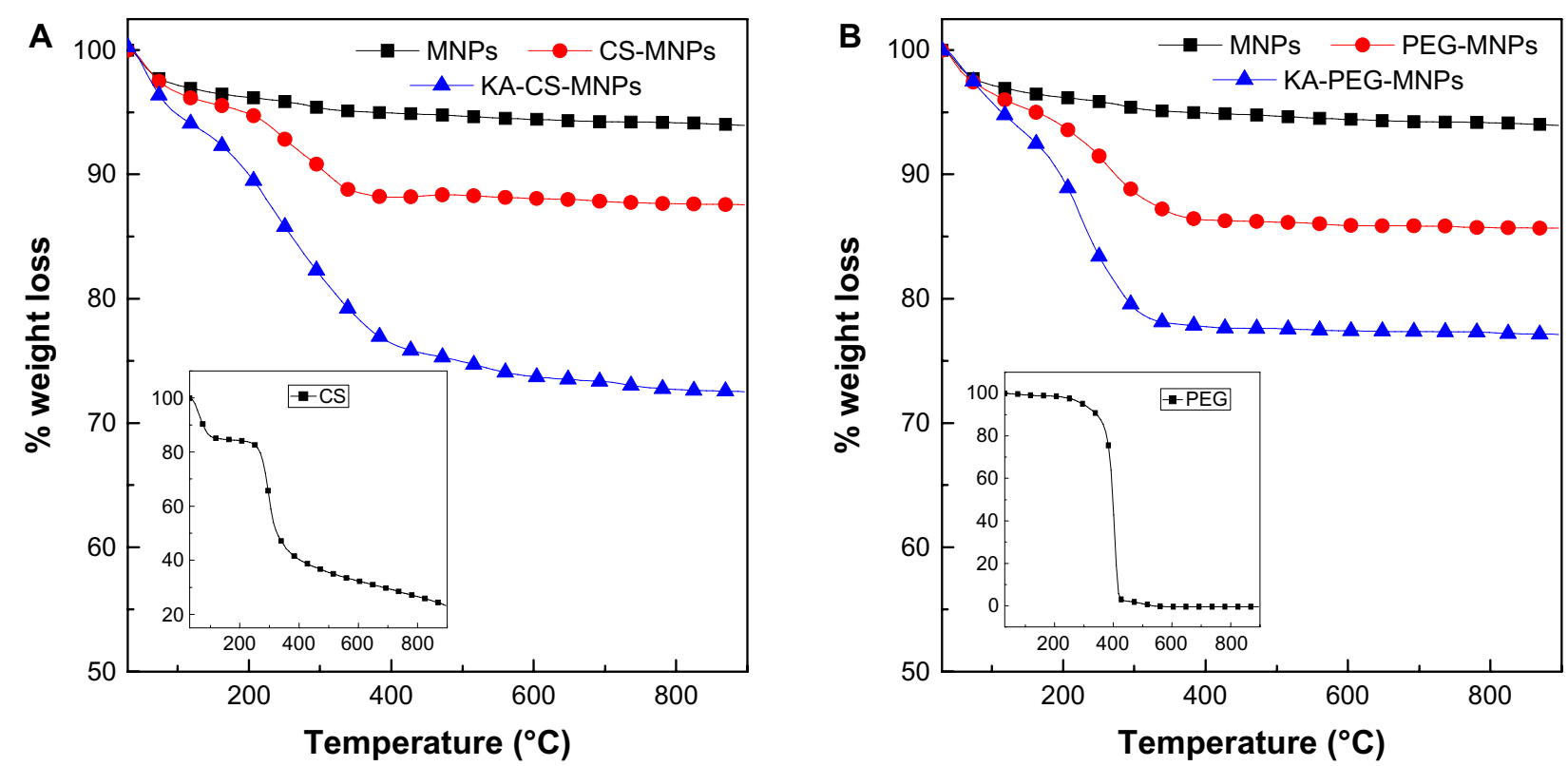

Figure 4 TGA curves for MNPs, CS-MNPs, and KA-CS-MNPs (A) and MNPs, PEG-MNPs, and KA-PEG-MNPs (B), with insets showing the TGA curves of pure CS and PEG, respectively.

Abbreviations: CS, chitosan; CS-MNPs, chitosan-iron oxide nanoparticles; KA-CS-MNPs, kojic acid-chitosan-iron oxide nanoparticles; KA-PEG-MNPs, kojic acidpolyethylene glycol-iron oxide nanoparticles; MNPs, iron oxide magnetic nanoparticles; PEG, polyethylene glycol; PEG-MNPs, polyethylene glycol-iron oxide nanoparticles; TGA, thermogravimetry analysis.

loss is attributed to the decomposition of polymers and KA drugs.

The ultraviolet-visible spectrometry results, which were used to calculate the loading of KA in the final nanocomposites, gave $12.2 \%$ and $8.3 \%$ for the KA-CS-MNPs and KA-PEG-MNPs nanocomposites, respectively (data not shown).

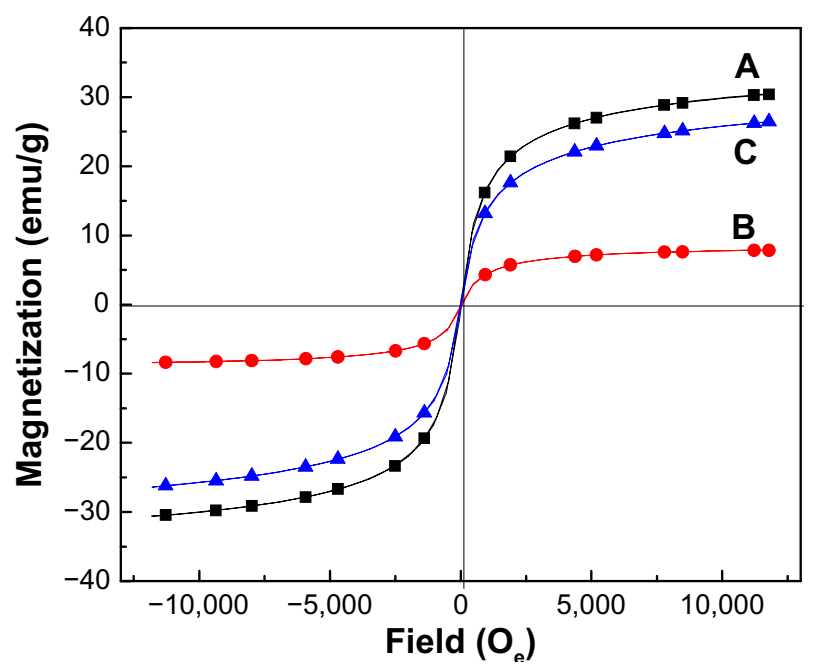

Figure 5 Magnetization curves of (A) MNPs, (B) KA-CS-MNPs, and (C) KA-PEGMNPs nanocomposites recorded at room temperature.

Abbreviations: KA-CS-MNPs, kojic acid-chitosan-iron oxide nanoparticles; KA-PEG-MNPs, kojic acid-polyethylene glycol-iron oxide nanoparticles; MNPs, iron oxide magnetic nanoparticles, $\mathrm{O}_{\mathrm{e}}$, applied magnetic field.

\section{Measurement of magnetic properties}

The results in Figure 5 show a typical magnetization $\left(\mathrm{M}_{\mathrm{s}}\right)$ versus the applied magnetic field plot at room temperature for MNPs, KA-CS-MNPs, and KA-PEG-MNPs nanocomposites. The $\mathrm{M}_{\mathrm{s}}$ curves of MNPs showed superparamagnetic properties (ie, no remanence effect) and saturation $\mathrm{M}_{\mathrm{s}}$ of about $30.5 \mathrm{emu} / \mathrm{g}$. As can be seen from Figure 5, similar to magnetite particles, KA-CS-MNPs and KA-PEG-MNPs nanocomposites also indicated a zero remanence $\mathrm{M}_{\mathrm{s}}$ and coercivity, thus suggesting that the superparamagnetic behavior is still retained with the nanocomposite materials. The saturation $M_{s}$ for KA-CS-MNPs and KA-PEG-MNPs nanocomposites were approximately $8.1 \mathrm{emu} / \mathrm{g}$ and $26.4 \mathrm{emu} / \mathrm{g}$, respectively. It can be seen from Figure 5 that the $\mathrm{M}_{\mathrm{s}}$ of the MNPs decreased in the final products. The decrease in $\mathrm{M}_{\mathrm{s}}$ value is only due to the exchange of electrons between the surface of $\mathrm{Fe}$ atoms with the CS and PEG polymers, ${ }^{55-57}$ providing further supporting evidence that the coating of CS and PEG did occur on MNPs.

\section{SEM analysis}

The SEM images of the pure MNPs and the KA-CSMNPs and KA-PEG-MNPs nanocomposites are shown in Figure 6. The agglomeration of the synthesized MNPs was very strong due to the van der Waals forces between the particles. ${ }^{58}$ After the surface coating, the agglomeration of 
50,000 magnifications
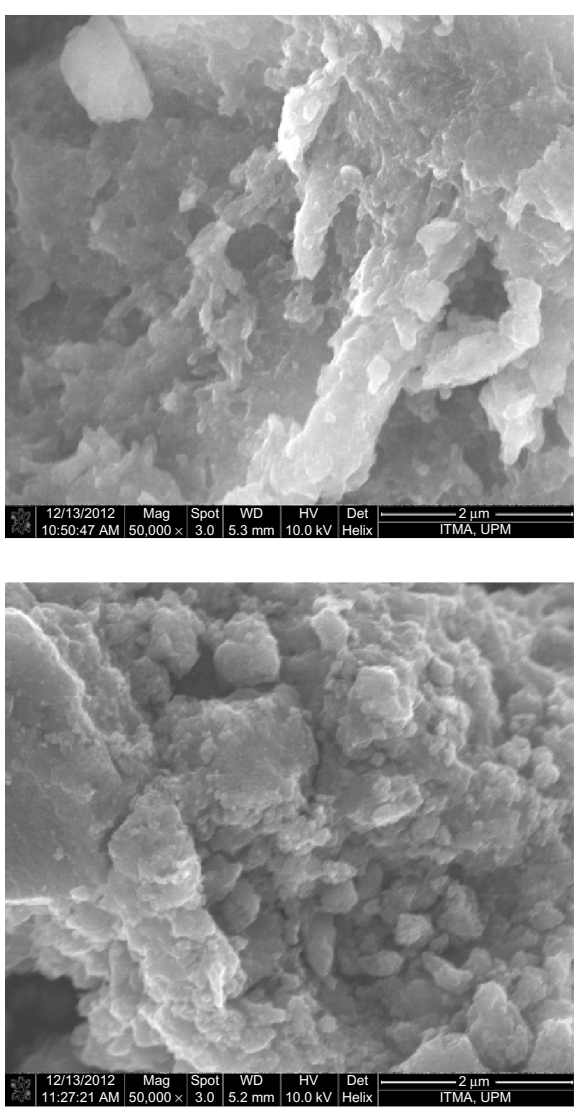

KA-CS-MNPs

KA-PEG-MNPs

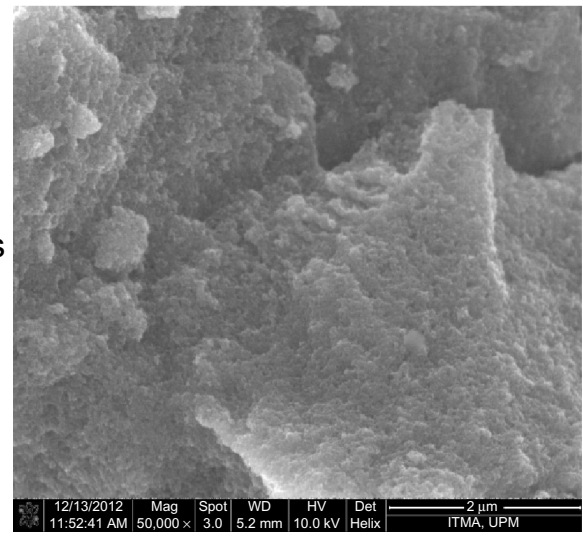

100,000 magnifications
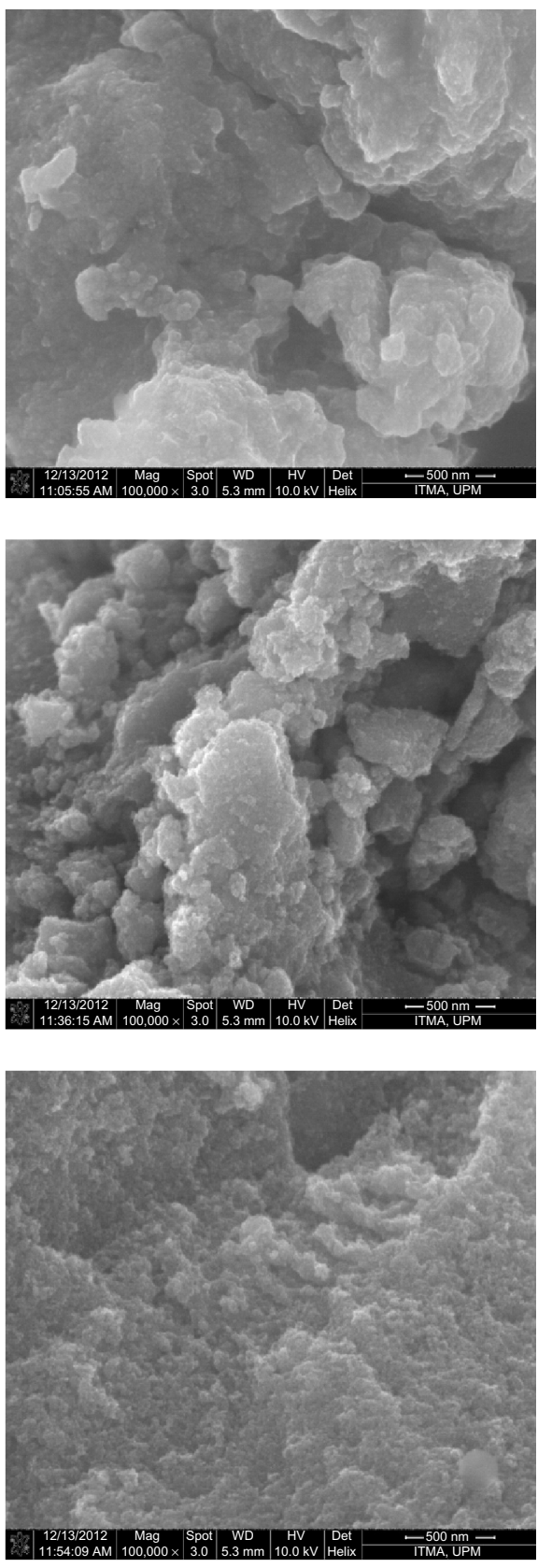

Figure 6 Scanning electron microscopy images of MNPs, KA-CS-MNPs, and the KA-PEG-MNPs.

Abbreviations: KA-CS-MNPs, kojic acid-chitosan-iron oxide nanoparticles; KA-PEG-MNPs, kojic acid-polyethylene glycol-iron oxide nanoparticles; MNPs, iron oxide magnetic nanoparticles.

the KA-CS-MNPs and KA-PEG-MNPs nanocomposites was reduced. This result indicated that the coating of the MNPs with CS and PEG decreased van der Waals forces between the MNPs. ${ }^{59}$ The agglomeration observed in Figure 6 also provides insights into the antibacterial properties presented in the discussion below, as those particles with greater agglomeration decreased bacteria interactions and surface area exposure.

\section{In vitro release study of $K A$ from the nanocomposites}

The release profiles of KA from the KA-CS-MNPs and KAPEG-MNPs nanocomposites and the physical mixture of KA with polymers and MNPs are shown in Figure 7. It can be seen from Figure 7A that the physical mixture of KA with polymers and MNPs exposed to a $\mathrm{pH}$ of 7.4 released KA quickly; the release was completed within 10 minutes. The release 

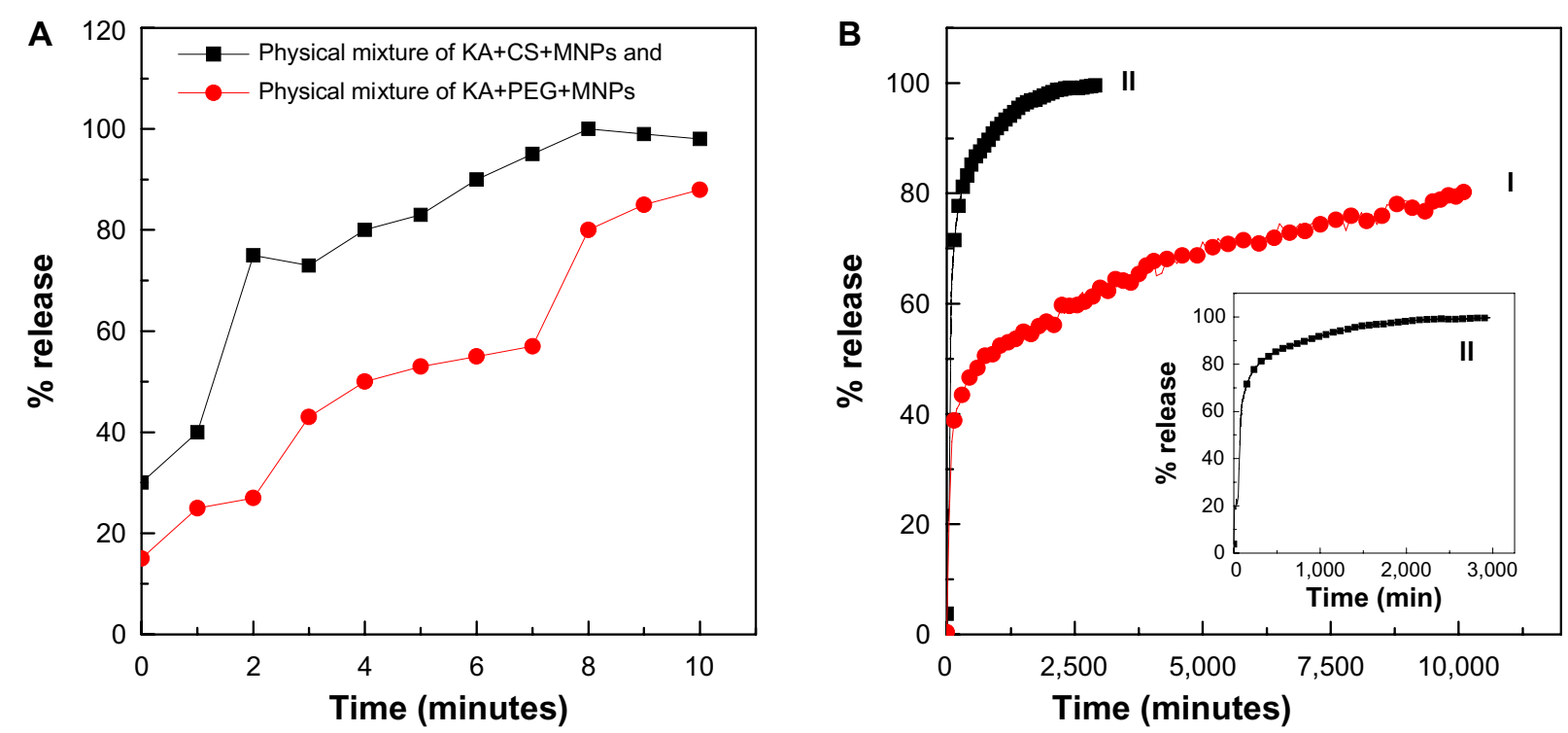

Figure 7 (A) Release profiles of KA from the physical mixture of KA+MNPs+CS or KA+MNPs+PEG at pH 7.4, and (B) release profiles of KA from the KA-CS-MNPs (I) and KA-PEG-MNPs (II) nanocomposites at pH 7.4. Inset in (B) shows the release profiles of KA from KA-PEG-MNPs.

Abbreviations: KA, kojic acid; KA+CS+MNPs, physical mixture of kojic acid, chitosan, and iron oxide nanoparticles; KA-CS-MNPs, kojic acid-chitosan-iron oxide nanoparticles; KA+PEG+MNPs, physical mixture of kojic acid, polyethylene glycol, and iron oxide nanoparticles; KA-PEG-MNPs, kojic acid-polyethylene glycol-iron oxide nanoparticles.

rate of KA from the KA-CS-MNPs and KA-PEG-MNPs nanocomposites are obviously slower than that from the physical mixture as shown in the Figure $7 \mathrm{~B}$, indicating that both the nanocomposites are potential drug controlled release systems which can be further tailored in future studies for specific applications. The slower release may be attributed to the hydrogen bond interactions between the polymers and KA as well as the aggregations that occurred in these nanocomposites.

The percentage release of KA from the KA-CSMNPs nanocomposite reached about $81.0 \%$ within about 8,000 minutes (Figure 7B, I) compared to about $99.8 \%$ within about 2,000 minutes (Figure 7B, II). The differences in the release rate of KA from KA-CS-MNPs and KA-PEG-MNPs nanocomposites may be due to the difference in number of hydrogen bonds which formed between the KA and polymers. In Figure 3, we can see the number of possible hydrogen bonds formed between the drug and CS was more than KA and PEG.

\section{Release kinetics of KA from KA-CS-MNPs and KA-PEG-MNPs}

The release behavior of KA from the KA-CS-MNPs and KA-PEG-MNPs nanocomposites can be described by different kinetics models, pseudo first-order (Equation 2), ${ }^{60}$ pseudo second-order (Equation 3), ${ }^{10} \mathrm{Higu}-$ chi model (Equation 4), ${ }^{61}$ Hixson-Crowell model
(Equation 5), ${ }^{61}$ and the Korsmeyer-Peppas model (Equation 6); ${ }^{61}$

$$
\begin{gathered}
\ln \left(\mathrm{q}_{\mathrm{e}}-\mathrm{q}_{\mathrm{t}}\right)=\ln \mathrm{q}_{\mathrm{e}}-\mathrm{kt} \\
\mathrm{t} / \mathrm{q}_{\mathrm{t}}=1 / \mathrm{k} \mathrm{q}_{\mathrm{e}}^{2}+\mathrm{t} / \mathrm{q}_{\mathrm{e}} \\
\mathrm{q}_{\mathrm{t}}=\mathrm{K} \sqrt{\mathrm{t}} \\
\sqrt[3]{\mathrm{M}_{\mathrm{o}}}-\sqrt[3]{\mathrm{M}_{\mathrm{t}}}=\mathrm{Kt} \\
\frac{\mathrm{q}_{\mathrm{t}}}{\mathrm{q}_{\infty}}=K t^{\mathrm{n}}
\end{gathered}
$$

where $\mathrm{q}_{\mathrm{e}}$ and $\mathrm{q}_{\mathrm{t}}$ are the equilibrium release amount and the release amount at any time $(\mathrm{t})$, respectively, and $\mathrm{M}_{\mathrm{o}}$ and $\mathrm{M}_{\mathrm{t}}$ are the initial amount and the amount of the drug in the nanocomposite at time $t$, respectively.

With the use of the five kinetic models as mentioned earlier in the release kinetic data, it was found that the pseudo second-order model is more satisfactory for describing the release kinetic processes of KA from the KA-CS-MNPs and KA-PEG-MNPs nanocomposites compared to the other models used in this work. Figure 8 shows the plots of $t / q_{t}$ against time for the pseudo second-order kinetic model, and the resulting correlation coefficient as well as the rate constant k-values are given in Table 1. 

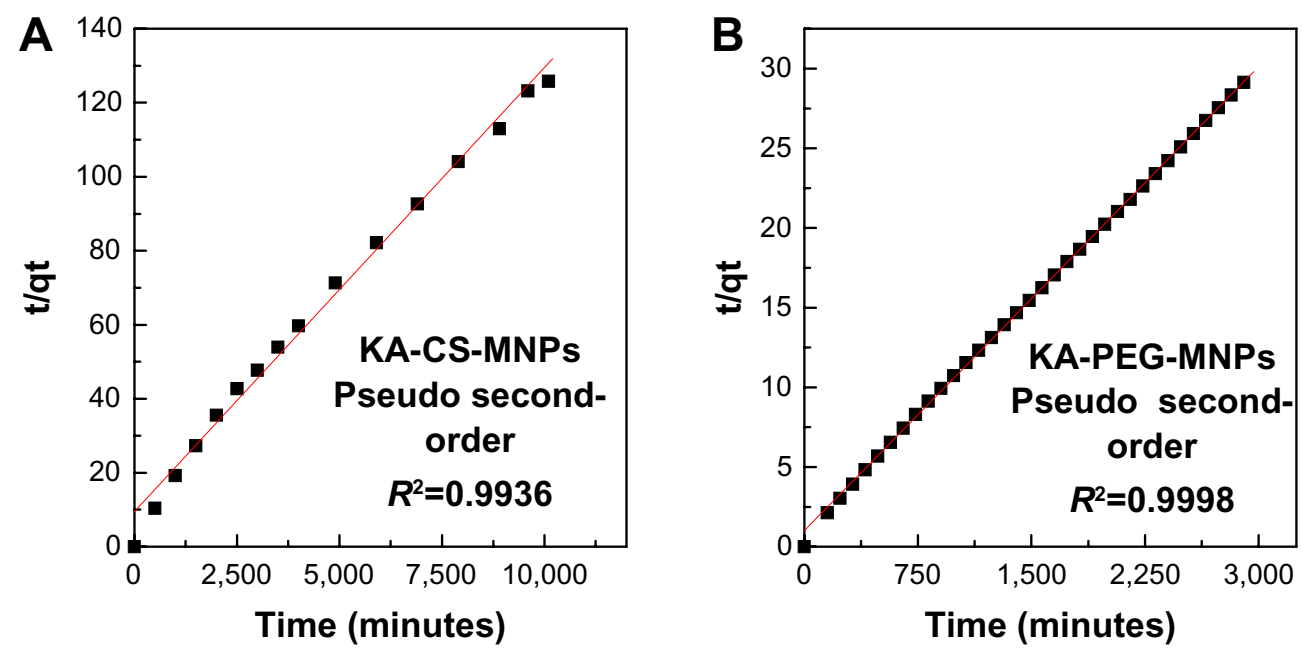

Figure 8 Fitting of data for KA release from (A) KA-CS-MNPs and (B) KA-PEG-MNPs nanocomposites for pseudo second-order kinetic model at pH 7.4. Abbreviations: CS-MNPs, chitosan-iron oxide nanoparticles; KA, kojic acid; PEG-MNPs, polyethylene glycol-iron oxide nanoparticles; KA-CS-MNPs, kojic acid-chitosaniron oxide nanoparticles; KA-PEG-MNPs, kojic acid-polyethylene glycol-iron oxide nanoparticles.

\section{In vitro antimicrobial activity of the KA nanocomposites}

In the present study, the antimicrobial activity of the synthesized KA-CS-MNPs nanocomposite was determined using an agar-based method against three bacterial strains of clinical significance, which can cause a range of minor to lifethreatening infections in the skin due to burns and respiratory, urinary tract, gastrointestinal, or blood infections (Figure 9). The antimicrobial activity of the MNPs alone as well as the KA loaded nanocomposites were tested, and it was found that MNPs did not show any antimicrobial effect on the microorganisms tested (data not shown). In contrast, the KA-CSMNPs and KA-PEG-MNPs nanocomposites showed minimal to no antimicrobial activity against the selected microorganisms under the test conditions using the agar diffusion method as compared to the free $\mathrm{KA}$, which showed comparable to less antimicrobial activity, in agreement with previous studies. Further investigation into optimal drug loading, polymer degradation, etc will improve the antimicrobial activity of the KA incorporated novel nanocomposites. Specifically, for
Bacillus subtilis, the zone of inhibition was one-half for KA alone and one-tenth for KA-CS-MNPs compared to controls. For methicillin-resistant Staphylococcus aureus, the zone of inhibition was two-thirds for KA alone and one-tenth for KACS-MNPs compared to controls. For Salmonella enterica, the zone of inhibition was one-half for KA alone and was one-fifteenth for the KA-CS-MNPs compared to controls. At the drug concentrations used and time point studied, no zone of inhibition was clearly observed for any of the bacteria and KA-PEG-MNPs. Such results may be expected due to the aforementioned decreased KA loading for KA-PEG-MNPs compared to KA-CS-MNPs.

The antimicrobial activity of KA and its derivatives against a number of microorganisms was reported previously; $29,45,48,62,63$ there are no similar reports in the literature for KA nanocomposites. Incorporating other derivatives of KA of higher antibacterial activity may also reveal additional information towards understanding the antimicrobial activity of KA-polymer-nanocomposites and their applications. Nonetheless, this study provided critical evidence of KA loading into composites

Table I Correlation coefficients $\left(R^{2}\right)$ obtained by fitting the KA release data from KA-CS-MNPs and KA-PEG-MNPs nanocomposites in phosphate-buffered saline solutions at $\mathrm{pH} 7.4$

\begin{tabular}{lllllll}
\hline Samples & $\begin{array}{l}\text { Saturation } \\
\text { release (\%) }\end{array}$ & $\begin{array}{l}\text { Pseudo first- } \\
\text { order }\end{array}$ & $\begin{array}{l}\text { Pseudo second- } \\
\text { order }\end{array}$ & $\begin{array}{l}\text { Higuchi } \\
\text { model }^{62}\end{array}$ & $\begin{array}{l}\text { Hixson-Crowell } \\
\text { model }^{61}\end{array}$ & $\begin{array}{l}\text { Korsmeyer-Peppas } \\
\text { model }^{61}\end{array}$ \\
\hline KA-CS-MNPs & 81.0 & 0.9661 & 0.9936 & 0.9168 & 0.9066 & 0.9726 \\
KA-PEG-MNPs & 99.8 & 0.9936 & 0.9998 & 0.8457 & 0.9609 & 0.9026 \\
\hline
\end{tabular}

Abbreviations: CS-MNPs, chitosan-iron oxide nanoparticles; KA, kojic acid; KA-CS-MNPs, kojic acid-chitosan-iron oxide nanoparticles; KA-PEG-MNPs, kojic acidpolyethylene glycol-iron oxide nanoparticles; PEG-MNPs, polyethylene glycol-iron oxide nanoparticles. 

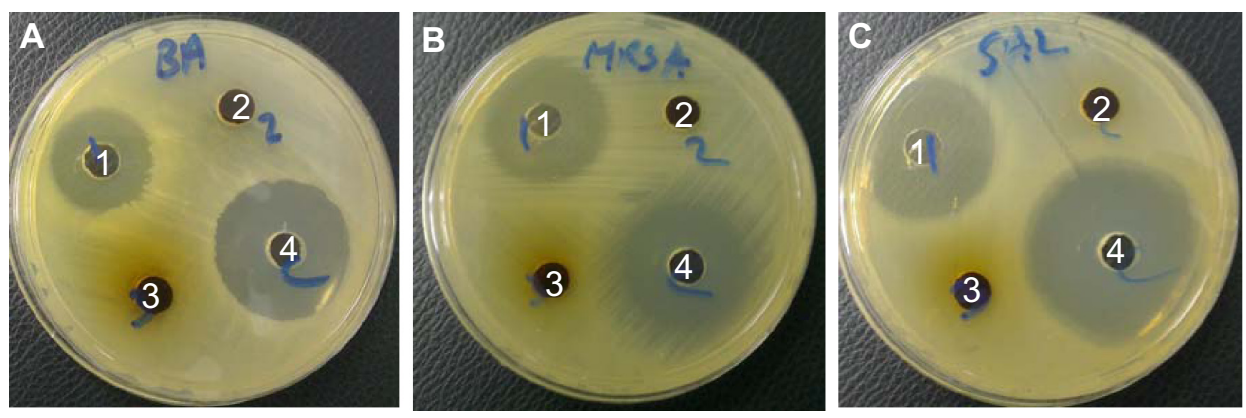

Figure 9 Antimicrobial activity of I) kojic acid, 2) KA-CS-MNPs, and 3) KA-PEG-MNPs nanocomposites using an agar diffusion method against different microorganisms. Notes: (A) Bacillus subtilis, (B) methicillin-resistant Staphylococcus aureus, and (C) Salmonella choleraesuis showing the antimicrobial activity of I), whereby 2) showed some and 3) lacked antimicrobial activity as compared to control antibiotics 4).

Abbreviations: KA-CS-MNPs, kojic acid-chitosan-iron oxide nanoparticles; KA-PEG-MNPs, kojic acid-chitosan-iron oxide nanoparticles.

as a new strategy into nanoantimicrobials to treat microbial infections that can be enhanced in further studies.

\section{Conclusion}

KA-CS-MNPs and KA-PEG-MNPs nanocomposites were prepared in this work. The attachment of the CS and PEG onto the MNPs surface was revealed by FTIR, similarly to the loaded KA. However, studies in the biological activities of KA nanocomposites have been limited, and this study is the first to report a novel nanocomposite for biomedical applications. Whereby, this work only detected minimal antimicrobial activity for the KA-CS-MNPs nanocomposite against the tested microorganisms, further studies on the possible biological activities are underway. Thus, this study provided promising evidence for KA and KA-CS-MNPs in antibacterial applications, and their potential therapeutic role deserves further attention.

\section{Acknowledgment}

The authors would like to thank the Malaysian Ministry of Higher Education for supporting this research to be conducted in Universiti Putra Malaysia under grant ERGS/1/11/ STG/UPM/01/18 (vote 5527050).

\section{Disclosure}

The authors report no conflicts of interest in this work.

\section{References}

1. Barrett AP. A long-term prospective clinical study of oral complications during conventional chemotherapy for acute leukemia. Oral Surg Med Path. 1987;63(3):313-316.

2. Branda RF, Naud SJ, Brooks EM, Chen Z, Muss H. Effect of vitamin $\mathrm{B} 12$, folate, and dietary supplements on breast carcinoma chemotherapyinduced mucositis and neutropenia. Cancer. 2004;101(5):1058-1064.

3. Danilenko DM, Ring BD, Yanagihara D, et al. Keratinocyte growth factor is an important endogenous mediator of hair follicle growth, development, and differentiation. Normalization of the nu/nu follicular differentiation defect and amelioration of chemotherapy-induced alopecia. Am J Pathol. 1995;147(1):145-154.
4. Akbulut M, D'Addio SM, Gindy ME, Prud'homme RK. Novel methods of targeted drug delivery: the potential of multifunctional nanoparticles. Expert Rev Clin Pharmacol. 2009;2(3):265-282.

5. Chari RV. Targeted cancer therapy: conferring specificity to cytotoxic drugs. Acc Chem Res. 2007;41(1):98-107.

6. Kim S, Kim JY, Huh KM, Acharya G, Park K. Hydrotropic polymer micelles containing acrylic acid moieties for oral delivery of paclitaxel. J Controlled Release. 2008;132(3):222-229.

7. Tran N, Webster TJ. Magnetic nanoparticles: biomedical applications and challenges. J Mater Chem. 2010;20(40):8760-8767.

8. Mahmoudi M, Sant S, Wang B, Laurent S, Sen T. Superparamagnetic iron oxide nanoparticles (SPIONs): development, surface modification and applications in chemotherapy. Adv Drug Deliv Rev. 2011;63(1-2):24-46.

9. Gupta AK, Gupta M. Synthesis and surface engineering of iron oxide nanoparticles for biomedical applications. Biomaterials. 2005;26(18):3995-4021.

10. Alexiou C, Schmid RJ, Jurgons R, et al. Targeting cancer cells: magnetic nanoparticles as drug carriers. Eur Biophys J. 2006;35(5):446-450.

11. Pankhurst QA, Connolly J, Jones SK, Dobson J. Applications of magnetic nanoparticles in biomedicine. J Phys D Appl Phys. 2003; 36(13):R167.

12. Alexiou C, Arnold W, Hulin P, et al. Magnetic mitoxantrone nanoparticle detection by histology, X-ray and MRI after magnetic tumor targeting. J Magn Magn Mater. 2001;225(1-2):187-193.

13. Jain TK, Morales MA, Sahoo SK, Leslie-Pelecky DL, Labhasetwar V. Iron oxide nanoparticles for sustained delivery of anticancer agents. Mol Pharm. 2005;2(3):194-205.

14. Kaaki K, Hervé-Aubert K, Chiper M, et al. Magnetic nanocarriers of doxorubicin coated with poly(ethylene glycol) and folic acid: relation between coating structure, surface properties, colloidal stability, and cancer cell targeting. Langmuir. 2012;28(2):1496-1505.

15. Kayal S, Ramanujan RV. Doxorubicin loaded PVA coated iron oxide nanoparticles for targeted drug delivery. Mater Sci Eng C. 2010;30(3):484-490.

16. Quan Q, Xie J, Gao H, et al. HSA coated iron oxide nanoparticles as drug delivery vehicles for cancer therapy. Mol Pharm. 2011;8(5): 1669-1676.

17. Saboktakin MR, Tabatabaie R, Maharramov A, Ramazanov MA. Synthesis and characterization of superparamagnetic chitosan-dextran sulfate hydrogels as nano carriers for colon-specific drug delivery. Carbohydr Polym. 2010;81(2):372-376.

18. Finotelli PV, Da Silva D, Sola-Penna M, et al. Microcapsules of alginate/chitosan containing magnetic nanoparticles for controlled release of insulin. Colloids Surf B Biointerfaces. 2010;81(1):206-211.

19. Qu JB, Shao HH, Jing GL, Huang F. PEG-chitosan-coated iron oxide nanoparticles with high saturated magnetization as carriers of 10-hydroxycamptothecin: preparation, characterization and cytotoxicity studies. Colloids Surf B Biointerfaces. 2013;102:37-44. 
20. Dorniani D, Hussein MZ, Kura AU, Fakurazi S, Shaari AH, Ahmad Z. Preparation of $\mathrm{Fe}_{3} \mathrm{O}_{4}$ magnetic nanoparticles coated with gallic acid for drug delivery. Int J Nanomedicine. 2012;7:5745-5756.

21. Sun C, Sze R, Zhang M. Folic acid-PEG conjugated superparamagnetic nanoparticles for targeted cellular uptake and detection by MRI. J Biomed Mater Res A. 2006;78(3):550-557.

22. Arias JL, López-Viota M, López-Viota J, Delgado AV. Development of iron/ethylcellulose (core/shell) nanoparticles loaded with diclofenac sodium for arthritis treatment. Int J Pharm. 2009;382(1-2):270-276.

23. Butoescu N, Jordan O, Burdet P, et al. Dexamethasone-containing biodegradable superparamagnetic microparticles for intra-articular administration: physicochemical and magnetic properties, in vitro and in vivo drug release. Eur J Pharm Biopharm. 2009;72(3):529-538.

24. Beélik A. Kojic acid. Adv Carbohydr Chem. 1956;48(11):145-183.

25. Morton HE, Kocholaty W, Junowicz-Kocholaty R, Kelner A. Toxicity and antibiotic activity of kojic acid produced by Aspergillus luteo-virescens. J Bacteriol. 1945;50(5):579-584.

26. Prescott SC, Dunn CG. Industrial Microbiology. New York, NY: McGraw-Hill; 1940.

27. Yaduta T. Kojic acid, a new organic acid formed by Aspergillus oryzae. J. Chem Soc. Japan, 1916;37:1185-1233.

28. Aytemir MD, Karakaya G, Ekinci D. Kojic acid derivatives. In: Deniz Ekinci, editor. Medicinal Chemistry and Drug Design. 2012:1-26. Available from: http://www.intechopen.com/books/medicinalchemistry-and-drug-design/kojic-acid-derivatives.

29. Brtko J, Rondahl L, Ficková M, Hudecová D, Eybl V, Uher M. Kojic acid and its derivatives: history and present state of art. Cent Eur J Public Health. 2004;12 Suppl:S16-S18.

30. Mohamad R, Mohamed $M_{s}$, Suhaili N, Salleh MM, Ariff AB. Kojic acid: applications and development of fermentation process for production. Biotechnol Mol Biol Rev. 2010;5(2):24-37.

31. Aytemir MD, Septioğlu E, Caliş U. Synthesis and anticonvulsant activity of new kojic acid derivatives. Arzneimittelforschung. 2010;60(1):22-29.

32. Iyengar R, McEvily AJ. Anti-browning agents: alternatives to the use of sulfites in foods. Trends Food Sci Technol. 1992;3:60-64.

33. Uchino K, Nagawa M, Tonosaki Y, Oda M, Fukuchi A. Kojic acid as an anti-speck agent (foof and nutrition). Agric Biol Chem. 1988;52(10): 2609-2610.

34. Bentley R. From miso, saké and shoyu to cosmetics: a century of science for kojic acid. Nat Prod Rep. 2006;23(6):1046-1062.

35. Mishima Y, Hatta S, Ohyama Y, Inazu M. Induction of melanogenesis suppression: cellular pharmacology and mode of differential action. Pigment Cell Res. 1988;1(6):367-374.

36. Choi CM, Berson DS. Cosmeceuticals. Seminars in Cutaneous Medicine and Surgery. 2006;25(3):163-168.

37. Cabanes J, Chazarra S, Garcia-Carmona F. Kojic acid, a cosmetic skin whitening agent, is a slow-binding inhibitor of catecholase activity of tyrosinase. J Pharm Pharmacol. 1994;46(12):982-985.

38. Beard RL, Walton GS. Kojic acid as an insecticidal mycotoxin. $J$ Invertebr Pathol. 1969;14(1):53-59.

39. Veverka M. Synthesis of some biologically active derivatives of 2-hydroxymethyl-5-hydroxy-4H-pyran-4-one. 2. Synthesis and biological properties of S-substituted 2-thiomethyl-5-O-acyl derivatives. Chem Pap. 1992;46(3):206-210.

40. Alverson J, Cohen AC. Effect of antifungal agents on biological fitness of Lygus hesperus (Heteroptera: Miridae). J Econ Entomol. 2002;95(2):256-260.

41. Higa Y, Kawabe M, Nabae K, et al. Kojic acid-absence of tumorinitiating activity in rat liver, and of carcinogenic and photo-genotoxic potential in mouse skin. J Toxicol Sci. 2007;32(2):143-159.

42. Xiong X, Pirrung MC. Modular synthesis of candidate indole-based insulin mimics by Claisen rearrangement. Org Lett. 2008;10(6):1151-1154.

43. Yamato M, Hashigaki K, Yasumoto Y, et al. Synthesis and antitumor activity of tropolone derivatives. 6. Structure-activity relationships of antitumor-active tropolone and 8-hydroxyquinoline derivatives. $J \mathrm{Med}$ Chem. 1987;30(10):1897-1900.
44. Fickova M, Pravdova E, Rondhal L, Uher M, Brtko J. In vitro antiproliferative and cytotoxic activities of novel kojic acid derivatives: 5-benzyloxy-2-selenocyanatomethyl- and 5-methoxy2-selenocyanatomethyl-4-pyranone. J Appl Toxicol. 2008;28(4): 554-559.

45. Hudecová D, Uher M, Brtko J. Halogen derivatives of kojic acid with antifungal effects. Biologia. 1992;47:483-488.

46. Nohynek GJ, Kirkland D, Marzin D, Toutain H, Leclerc-Ribaud C, Jinnai $\mathrm{H}$. An assessment of the genotoxicity and human health risk of topical use of kojic acid [5-hydroxy-2-(hydroxymethyl)-4H-pyran-4one]. Food Chem Toxicol. 2004;42(1):93-105.

47. Kim JH, Chang PK, Chan KL, et al. Enhancement of commercial antifungal agents by kojic Acid. Int J Mol Sci. 2012;13(11):13867-13880.

48. Chee HY, Lee EH. Fungistatic activity of kojic acid against human pathogenic fungi and inhibition of melanin-production in Cryptococcus neoformans. Mycobiology. 2003;31(4):248-250.

50. Rodrigues AP, Carvalho AS, Santos AS, Alves CN, do Nascimento JL, Silva EO. Kojic acid, a secondary metabolite from Aspergillus sp, acts as an inducer of macrophage activation. Cell Biol Int. 2011;35(4): $335-343$.

51. National Committee for Clinical Laboratory Standards. Methods for Dilution of Antimicrobial Susceptibility Test for Bacteria that Grow Aerobically. 4th ed. Approved Standard NCCLS Document M7-A4, Vol 17, No 2. Wayne, PA: NCCLS; 1997.

52. Unsoy G, Yalcin S, Khodadust R, Gunduz G, Gunduz U. Synthesis optimization and characterization of chitosan-coated iron oxide nanoparticles produced for biomedical applications. J Nanopart Res. 2012;14(11):1-13

53. Marchessault RH, Ravenelle Fo, Zhu XX, editors. Polysaccharides for Drug Delivery and Pharmaceutical Applications. Vol 934. Washington, DC: American Chemical Society; 2006.

54. Jayanthi SA, Sukanya D, Pragasam AJA, Sagayaraj P. The influence of PEG 20,000 concentration on the size control and magnetic properties of functionalized bio-compatible magnetic nanoparticles. Der Pharma Chemica. 2013;5(1):90-102.

55. Kumar R, Inbaraj BS, Chen BH. Surface modification of superparamagnetic iron nanoparticles with calcium salt of poly $(\gamma$-glutamic acid) as coating material. Mater Res Bull. 2010;45(11):1603-1607.

56. Shan Z, Yang WS, Zhang X, Huang QM, Ye H. Preparation and characterization of carboxyl-group functionalized superparamagnetic nanoparticles and the potential for bio-applications. J Brazil Chem Soc. 2007;18(7):1329-1335.

57. $\mathrm{Yu} \mathrm{S}$, Chow GM. Carboxyl group $\left(-\mathrm{CO}_{2} \mathrm{H}\right)$ functionalized ferrimagnetic iron oxide nanoparticles for potential bio-applications. J Mater Chem. 2004;14(18):2781-2786.

58. Dung TT, Danh TM, Duc NH, Chien DM. Preparation and characterization of magnetic nanoparticles coated with polyethylene glycol. J Phys Conf Ser. 2009;187(1):012048.

59. Yue-Jian C, Juan T, Fei X, et al. Synthesis, self-assembly, and characterization of PEG-coated iron oxide nanoparticles as potential MRI contrast agent. Drug Dev Ind Pharm. 2010;36(10):1235-1244.

60. Dong L, Yan L, Hou WG, Liu SJ. Synthesis and release behavior of composites of camptothecin and layered double hydroxide. $J$ Solid State Chem. 2010;183(8):1811-1816.

61. Sakore S, Chakraborty B. Formulation and evaluation of enalapril maleate sustained release matrix tablets. Int J Pharm Biomed Res. 2013;4(1):21-26.

62. Baláz S, Uher M, Brtko J, et al. Relationship between antifungal activity and hydrophobicity of kojic acid derivatives. Folia Microbiol (Praha). 1993;38(5):387-391.

63. Aytemir MD, Özçelik B. Synthesis and biological activities of new Mannich bases of chlorokojic acid derivatives. Med Chem Res 2011;20(4):443-452. 


\section{Publish your work in this journal}

The International Journal of Nanomedicine is an international, peerreviewed journal focusing on the application of nanotechnology in diagnostics, therapeutics, and drug delivery systems throughout the biomedical field. This journal is indexed on PubMed Central, MedLine, CAS, SciSearch $\AA$, Current Contents ${ }^{\circledR} /$ Clinical Medicine,

Journal Citation Reports/Science Edition, EMBase, Scopus and the Elsevier Bibliographic databases. The manuscript management system is completely online and includes a very quick and fair peer-review system, which is all easy to use. Visit http://www.dovepress.com/ testimonials.php to read real quotes from published authors.

Submit your manuscript here: http://www.dovepress.com/international-journal-of-nanomedicine-journal 